\title{
Moral self-licencing and social dilemmas: an experimental analysis from a taking game in Madagascar
}

Article

Accepted Version

Clot, S., Grolleau, G. and Ibanez, L. (2018) Moral selflicencing and social dilemmas: an experimental analysis from a taking game in Madagascar. Applied Economics, 50 (27). pp. 2980-2991. ISSN 1466-4283 doi:

https://doi.org/10.1080/00036846.2017.1412083 Available at https://centaur.reading.ac.uk/74424/

It is advisable to refer to the publisher's version if you intend to cite from the work. See Guidance on citing.

To link to this article DOI: http://dx.doi.org/10.1080/00036846.2017.1412083

Publisher: Taylor \& Francis

All outputs in CentAUR are protected by Intellectual Property Rights law, including copyright law. Copyright and IPR is retained by the creators or other copyright holders. Terms and conditions for use of this material are defined in the End User Agreement.

www.reading.ac.uk/centaur 
Central Archive at the University of Reading

Reading's research outputs online 


\title{
Moral self-licensing and social dilemmas:
}

\section{An experimental analysis from a taking game in Madagascar}

\author{
Sophie Clot, GiLles GrolleAu AND LiSETTE IBANEZ \\ Sophie Clot (Co-author) \\ University of Reading
}

Whiteknights street, Reading, United Kingdom, E-mail : s.clot@reading.ac.uk

\section{Gilles Grolleau (Co-author)}

LAMETA, Montpellier SupAgro, INRA, CNRS, Univ. Montpellier

Univ. Bourgogne Franche-Comté, Burgundy School of Business-CEREN

29, Rue Sambin BP 50608, 21006 Dijon, France, E-mail: grolleau@supagro.inra.fr

Lisette Ibanez (Corresponding author)

LAMETA, INRA, Univ. Montpellier, CNRS, Montpellier SupAgro

2, PLACE Viala, 34060 MontPELlier CEDEX 1, E-mail: ibanez@supagro.inra.fr

\section{Summary}

This paper explores whether previous good deeds may license anti-social behavior, such as appropriating a social surplus for private benefits, in a developing country context, namely Madagascar. We design a two-step framed experiment, with one control treatment (a neutral task) and three test treatments (tasks enabling subjects to earn moral credits in 3 different ways), followed by a taking game in which subjects are given the opportunity to take an amount from a fund allocated to their University. On average, we find that participants in the three licensing conditions appropriate more than those in the control group, and that further differences emerge according to the way the moral credits have been earned.

Key words: Moral self-licensing, unethical behavior, behavioral experiment, taking game.

JEL codes: C91, D03. 


\section{Moral self-licensing and social dilemmas:}

\section{An experimental analysis from a taking game in Madagascar}

\section{INTRODUCTION}

A growing literature on moral self-licensing is providing new perspective on the motivational forces underlying moral behavior. Traditionally, social preferences and moral behavior have been considered to be exogenous and consistent over time (Narloch et al, 2012; Carpenter and Seki, 2010; Castillo and Saysel, 2005; Henrich, 2000). However, recent research suggests that performing a virtuous deed can impact future decisions, specifically by decreasing the willingness to act pro-socially in a subsequent situation, and vice versa (Khan and Dhar, 2006; Sachdeva et al., 2009; Mazar and Zhong, 2010; Blanken et al., 2015; Mullen and Monin, 2016, Clot et al., 2016). Anecdotal and empirical evidence shows, for example, that Prius Hybrid drivers are more likely to break crosswalk laws and receive fines, that consumers who purchase green products are more likely to steal, and that people who wrote positive stories about themselves are more likely to act selfishly, etc. (Woodyard, 2009; Mazar and Zhong, 2010, Sachdeva et al., 2009). In a similar vein, we conduct an experiment in a developing country that is designed to test the predictive ability of the 'moral credit model' (i.e. good deeds establish moral credits that can be likened to deposits in a bank account that can be 'withdrawn' to 'purchase' the right to perform bad deeds). We study behavior by observing choices in a social dilemma in which private and public interests diverge.

Although studies on pro-social preferences have proliferated in recent decades, much less is known about the motives underpinning antisocial behavior (Cox et al 2013). As a result, our work makes three principal contributions to the literature to date. First, mobilizing recent work in psychology, we propose a new approach for studying anti-social behavior (Khan and Dhar, 2006; Sachdeva et al., 2009; Mazar and Zhong, 2010; Chiou and al., 2011). A second originality of our paper is that we are the first to test the moral credit model in the context of a developing country. Indeed, all of the previous research on moral self-licensing has been conducted in Western countries (see Blanken et al. ,2015 for a meta-study), where we might 
suspect a WEIRD ${ }^{1}$ effect (Heinrich et al., 2010). Indeed, Heinrich et al. (2010) argue that using samples drawn entirely from WEIRD societies to study human nature can be misleading. ${ }^{2}$ Cardenas and Carpenter (2008) state that "many developing countries rely on local norms and rules of conduct to provide public goods and regulate extraction from common pool resources" and argue that these informal norms of fairness and justice depend on existing formal institutions (and laws in particular). Moreover, equity and fairness concerns have been shown to differ according to wealth (Armantier, 2006). For these reasons, it seems important to us to investigate other-regarding preferences in developing countries. A third originality of our paper consists in testing the impact of three different methods by which moral credits can be earned and the way in which this method influences subsequent moral self-licensing. Although moderators such as the method by which moral credits are earned may affect both the occurrence and the extent of the moral licensing effect, research on moral self-licensing moderators is still very scarce. The remainder of this paper proceeds as follows. An overview of the relevant literature is presented in section 2. We then present the experimental design and the procedures used to test our predictions in section 3. Section 4 provides the results and discussion. Section 5 concludes.

\section{LITERATURE REVIEW}

Increasingly, individual preferences are described as being comprised of a combination of self-interest and social preferences, implying that individuals strike a balance between self and group interests. Additionally, the social preferences considered by this literature are assumed to be a given (Narloch et al, 2012, Carpenter and Seki, 2010; Castillo and Saysel, 2005; Henrich, 2000), correlated with socio-economic and cultural characteristics, and vulnerable to being crowded out by exogenous mediators such as external regulations (Cardenas et al, 2000) and rewards (Vollan, 2008; Narloch et al, 2012). In contrast, the idea of moral self-licensing that has recently emerged argues that social preferences may be influenced by past behavior (Khan and Dhar, 2006; Mazar and Zhong, 2010; Clot et al 2016; see Blanken et al. 2015 for a meta study and Mullen and Monin 2016 for a comprehensive review).

1 WEIRD effect : Western, Educated, Industrialized, Rich, Democratic

2 As a colleague has pointed out, on the one hand, it is possible that students in Madagascar are a relatively homogeneous population in comparison to populations in experimental labs in Europe or North America, which can be more ethnically diverse and exhibit more heterogeneous behaviour. On the other hand, students in Madagascar could be considered a privileged population, as they tend to be richer than the rest of the population and have more opportunities. These two factors could have opposite effects on results concerning the licensing effect. 
'Moral self-licensing' refers to a situation in which being 'good' leads to more self-indulgent choices in a subsequent period (where the reverse situation is referred to as 'moral cleansing'). Khan and Dhar (2006) proposed a definition of moral self-licensing as a non-conscious effect that operates by providing a moral boost in self-concept, which subsequently increases the preference for a relatively immoral action by dampening the negative self attributions associated with such behavior. In other words, this mechanism corresponds to a process of moral accounting whereby good deeds are assimilated as moral credits and bad deeds as moral debits.

We proceed by reviewing several studies that have explored the moral self-licensing effect. Sachdeva et al (2009) showed how moral self-licensing could negatively impact pro-social preferences. In their experiment, participants who wrote a positive story about themselves were significantly less generous in a subsequent task, keeping more for themselves in a dictator game than participants who wrote a neutral story. In a study about green consumers, Mazar and Zhong (2010) reported that customers from a green store shared less money than customers from a conventional store. Green store customers were also more likely to adopt dubious behavior such as cheating and stealing. This study can be considered to provide evidence of a self-regulation process and specifically, that licensing may lead to moral transgressions. In the environmental domain, Panzone et al (2012) found that making environmentally-friendly choices in several areas of grocery shopping had a negative impact on sustainable food consumption. Tiefenbeck et al (2013) have also shown that residents who received weekly feedback on their water consumption lowered their water use (6\% on average), but they simultaneously increased their electricity consumption by $5.6 \%$ compared with control subjects. In another vein, Clot et al (2013) examined how financial rewards for good deeds impacted the occurrence of self-licensing behavior. The authors found that prefacing the dictator game with an unpaid good deed appears to license subsequent selfish behavior, whereas paying the dictator for the good deed dampens this effect. This experiment was based on hypothetical good deeds, which suggests that even imaginary good deeds can have the power to license a decrease in subsequent prosocial behavior. In an economic experiment in which subjects played a sequence of dictator game decisions, Branas-Garza et al. (2011) found that participants' donations to recipients in each round were negatively correlated with the amount they donated in the previous period. The authors explain this pattern as the result of a self-regulation mechanism: moral licensing (being selfish after being generous) and moral cleansing (being generous after being selfish). 
More recently, two studies have found that moral self-licensing increases anti-social behavior such as cheating (Clot et al, 2014, Gneezy et al, 2015). This experimental evidence supports our main behavioral hypothesis, which is that, under some circumstances, people who have obtained moral credits are more likely to act anti-socially later by, for instance, taking from a social surplus or a common account.

Interestingly, the nature of the good deed (whether it actual or hypothetical) does not substantially impact the presence of a licensing effect. Indeed, our literature review shows that the licensing effect occurs both after a realized good deed (e.g. buying green products) as well as after a 'hypothetical' establishment of moral worth (e.g. writing a positive story about oneself or imagining doing a good deed). In our view, the impact associated with a hypothetical good deed deserves special attention as it has direct implications for a real outcome (i.e. a hypothetical good deed can impact realized anti-social behavior). We therefore elect to focus on the impact of a good will statement (e.g. a hypothetical good deed) on subsequent social preferences.

Hypothesis: Given a trade-off between private and public benefits, stating one's good intentions for 'others' (at a cost to one's self) will lead individuals to be more anti-social in a subsequent decision, namely by prioritizing their private interests over public interests.

Although the idea of a moral regulation process is not entirely new (e.g. the transgression-compliance effect from Carlsmith and Gross, 1969), the recent expansion of related literature (mostly in psychology), coupled with an emerging consistency in economic modeling (Bénabou and Tirole, 2010), significantly the relevance of moral self-regulation as a topic for economic research. In line with these recent advances, we test to what extent moral self-licensing may encourage anti-social behavior such as reducing a social surplus in order to increase private benefits. To capture anti-social behavior, we implemented a 'taking game $^{3}$ (Cox et al., 2013), which differs from the standard dictator game with respect to the initial distribution of the endowment. In the taking game, the initial endowment is allocated to the receiver and the dictator decides how much he would like to take from this endowment. In our work, we implement a slightly different version of this game. In Bardsley (2008), each player is paired with a receiver who is an anonymous student. We implement a version of the taking game in which there is a single common

\footnotetext{
${ }^{3}$ Similar games could also be found in the literature under different labels such as the 'gangster game' (Eichenberger and Oberholzer-Gee, 1998) or 'taking game' (Bardsley,, 2008).
} 
receiver for all dictators, in this case a public institution. In sum, participants have the opportunity to take a part of an amount initially endowed to their home institution. A more detailed description of our design follows in the next section.

\section{EXPERIMENTAL DESIGN}

In our experiment, we address the question of how previous good deeds may license anti-social behavior. In order to exclude the potential for risk preferences to play a role in the decision, neither punishment nor repressive measures are part of the experimental design. Moreover, the game involves no strategic considerations in terms of monetary outcomes (participants' payoffs are independent from the decisions made by other participants). The game is therefore designed to isolate the temptation to appropriate a shared fund in order to enjoy private benefits. We design a two-step framed experiment with one control treatment and three test treatments, which we carry out among students in Madagascar. While the first step for the treatment groups consists of a task that enables participants to earn moral credits, the first step for the control group is a neutral task (unscrambling sentences). In the second step, participants are given the opportunity to take money from a fund allocated to their University.

\section{(a) Qualitative background}

Pretests were conducted in order to improve the design of the first step of the experiment. We conducted informal interviews in order to identify actions that are universally considered to be 'good deeds' in Madagascar, and we used a self-assessment scale to confirm that these "good deeds" do in fact generate moral credits.

Two good deeds were selected based on informal discussions with students. The first pertains to the environment surrounding the University. The campus is located in the Antananarivo hills, which is considered to be a very pleasant green setting. The surrounding area is generally well maintained, although litter is ubiquitous and rather noticeable. Students concerned with the appearance of their campus proposed cleaning the grounds as a good deed. The second good deed that was identified through discussions was the creation of a guidebook aimed at new students. Because many students are from rural areas and are unfamiliar with the campus and its surroundings, there was consensus that they would benefit from a book detailing useful information about the campus. 
To validate the selection of these two good deeds, we ran a pretest on a group of 53 students from the University of Antananarivo. Following the self-assessment method used by Khan and Dhar (2006), we asked subjects to indicate the extent to which they agree or disagree, on a scale from 1 to 7 (1="Strongly disagree", 7="Strongly agree"), with the following four statements: "I am compassionate", "I am sympathetic", "I am generous" and "I am helpful”. Khan and Dhar (2006) used these items because they exhibited a high degree of internal reliability (Cronbach's $\alpha=0.84$ ). Students were then randomly assigned to a licensing or a control condition. In the licensing condition, subjects were asked to imagine that they engaged in a volunteering activity, selecting one of the two good deed options. Students in the control group were asked to unscramble sentences. Results of the self-assessment scale show that participants evaluated themselves significantly more positively on the four self-assessment attributes if they had imagined performing a good deed (licensing group) than if they had not (control group) (see table 1), regardless of which good deed they chose. We therefore selected these tasks in order to induce the earning of moral credits in the first step of our experimental design.

Table 1. Mean self-assessment in licensing and control conditions.

\begin{tabular}{llllll}
\hline \multicolumn{1}{c}{ I am... } & \multicolumn{2}{c}{ Licensing $(\mathrm{N}=37)$} & \multicolumn{2}{c}{ Control $(\mathrm{N}=16)$} & \multicolumn{2}{c}{ Ranksum test $^{4}$} \\
\hline Compassionate & 5.216216 & $(0.2743683)$ & 4.1875 & $(0.3442232)$ & $\mathrm{z}=-2.251, \mathrm{p}=0.0244$ \\
Sympathetic & 5.459459 & $(0.264503)$ & 4.375 & $(0.4643544)$ & $\mathrm{z}=-1.956, \mathrm{p}=0.0505$ \\
Generous & 5.447368 & $(0.2376311)$ & 4.3125 & $(0.3619248)$ & $\mathrm{z}=-2.382, \mathrm{p}=0.0172$ \\
Helpful & 5.351351 & $(0.2853169$ & 4.375 & $(0.4552929)$ & $\mathrm{z}=-1.860, \mathrm{p}=0.0628$ \\
\hline
\end{tabular}

Note: The standard error of the mean is in brackets.

The second step consists of an adapted version of the taking game. Instead of the original pairwise player set-up (Bardsley, 2008), all players are paired with the University as the receiving player. Participants are informed that the University has been allocated funding by a research project, and that the money must be invested in the University's infrastructure. Subjects are given the opportunity to take any amount between 0 and 30,000 Ariary from this fund, and the instructions clearly state that whatever was taken from the fund would directly reduce the amount of funds available for the University's use. Thus, students are not only presented with the option to take, but also with a message emphasizing the negative impact of taking. The questionnaires include a choice table that presents all of the pay-off options, explicitly detailing the breakdown between the amount taken and what remains for the University.

\footnotetext{
${ }^{4}$ Non parametrical Ranksum tests were used due to the small sample size.
} 
The framing of the experiment highlights the conflict between using money for private benefits (appropriating funds for yourself) vs. for public benefits (leaving funds for the University's infrastructure). If social preferences are exogenous and consistent over time, as is traditionally assumed, then volunteering for the University should not make students more likely to take from a fund dedicated to improving the University's infrastructure. If volunteering does have an impact on the willingness to take from the fund, however, this would constitute evidence of a moral self-regulation process by which earning moral credits subsequently licenses an individual to engage in anti-social behavior.

\section{(b) Experimental procedure}

A total of 367 students from the University of Antananarivo participated in the experiment during one of their course lectures. ${ }^{5}$ All participants were unfamiliar with experimental games. We conducted 3 sessions in which participants were randomly assigned into one of four groups (one control treatment and three test treatments). Within each session, subjects were only allowed to talk to administrators. There was 1 administrator for every 20 participants. Students were arranged as they would be during an exam in order to ensure that their decisions were made in private. In order to minimize discussion and contamination between sessions, the sessions were split among 3 different departments ${ }^{6}$ in the university. Questionnaires were anonymous and identified by a unique number. The professors of these lectures were not involved in administering the experiments so as to minimize any potential experimenter demand effect.

Table 2. Game design ${ }^{7}$

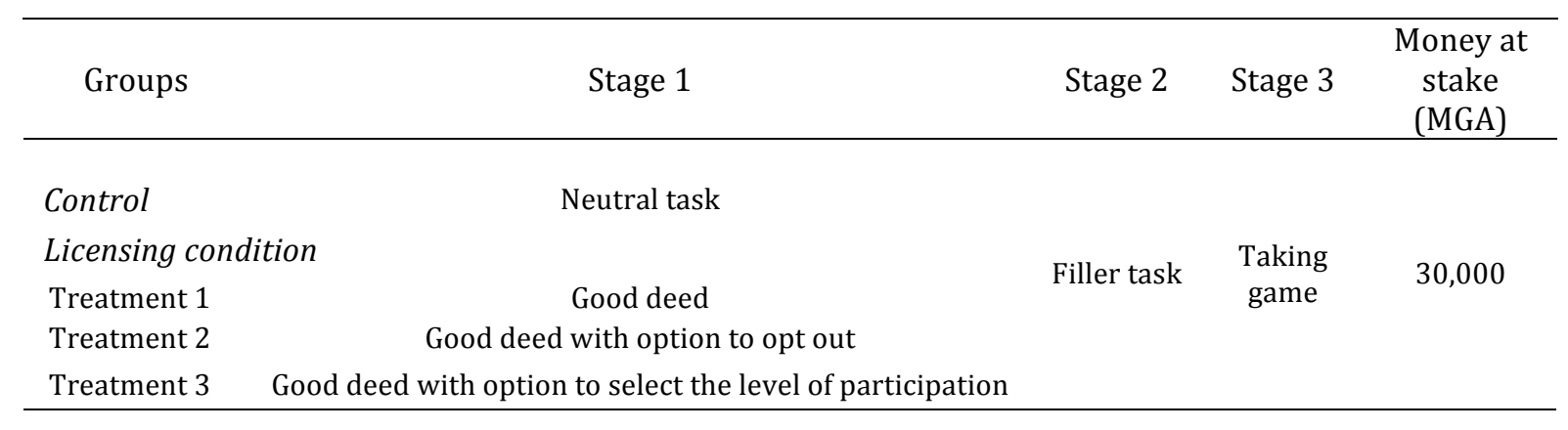

\footnotetext{
${ }^{5}$ We ensured that none of the students who had participated to either of the two pretests took part in the experiment. ${ }^{6}$ Sessions were carried out in the Department of Economics, the Department of Management, and the Department of Agriculture ${ }^{7}$ From a more conceptual viewpoint, individuals can be considered as making a moral decision in stage 1 and a financial decision in stage 3 . We contend that these decisions are not independent, but rather that they influence each other. Indeed, there appear to be interactions between the mental accounting and moral accounting processes, which is evidenced by various types of compensations, order effects, and reference points, which can also support multiple selves theories. A natural and worthwhile extension of this work would consist of formalizing these effects in a parsimonious behavioural model, but this task is beyond the scope of our paper.
} 
The experiment was comprised of three stages, which are illustrated in table 2. In the first stage, treatments 1, 2 and 3 were intended to induce an accumulation of moral credits (the 'moral self-licensing conditions') providing students the opportunity to establish a pro-social self-concept. In the control condition, this opportunity is replaced with a dummy task, which consists of unscrambling four sentences. The questionnaire length was therefore similar among all groups so as not to arouse suspicion among participants. This method was also used by Khan and Dhar (2006), who provide evidence that unscrambling sentences does not affect individual's self-concept.

In the licensing condition, we asked participants to imagine that they could volunteer for the University by either 1) 'cleaning buildings' surroundings' or 2) 'creating a guide book for new students'. All treatments proposed the same volunteering activities. However, we vary the way in which students in these treatments could respond and earn their moral credit. In treatment 1 , subjects could simply select one of the two good deeds. In treatment 2, subjects could also opt out of volunteering. Khan and Dhar (2006) used these options (with and without an opt-out clause) in two different experiments. They found evidence of a licensing effect in both experiments, but were unable to measure the magnitude of the effect. In treatment 3 , subjects could select the amount of time they wished to dedicate to the good deed (1 hour, 2 hours, 3 hours, half a day or a full day). This third treatment aims to reveal potential magnitude effects in the moral credit model (i.e. the more you invest in a pro-social activity, the greater the extent to which you feel licensed to act antisocially afterwards).

In the second stage, subjects were asked to describe the impact that this decision had on their self-concept (a filler task ${ }^{8}$ ). After completing stages 1 and 2, participants were invited to turn to the next sheet of the questionnaire. In stage 3, they were told that a foreign institution (LAMETA) had granted money to their University for infrastructure improvement (no specific information was given on the total amount granted). Measures were taken to convince students that their decisions will have real consequences on the grant offered to the University and on the improvement of its infrastructure. ${ }^{9}$ Both the oral

\footnotetext{
${ }^{8}$ A filler task was implemented to minimize the possibility that participants will perceive a link between the first and the third stages of the experiment (Khan and Dhar, 2006).

${ }^{9}$ We cannot entirely rule out the fact that some students may not have trusted this statement, but we assume that any potential impact that this may have had on decisions would be similar across treatments.
} 
instructions and individual questionnaires emphasized this point. Participants were told that they had the opportunity to take up to 30,000 Ariary out of this fund. A table of choices was provided that specified, for each option, the possible amounts that could taken from the fund and the amount that would remain for the University in each case. The instructions stated in capital and bold letters that the student's choice was real (i.e. not hypothetical) and confidential. It is also clearly stated that any amount that was taken for oneself would directly reduce the amount available for improving the University's infrastructure. Two checkboxes were offered: "I choose to take in the common fund", followed by a space in which participants could specify the amount (in increments of 1000, up to 30,000 Ariary), versus "I choose not to take in the common fund". The questionnaires were then collected and a lottery determined which participants were selected to be paid according to the choice they made in the game. One in ten participants was selected for payment.

This payment method, called a 'Random Incentivized System', has been studied by Armantier (2006), who compared results between a sure and a random gain and found no significant difference. In addition, Camerer and Hogarth (1999; see also Locey et al., 2011) demonstrated that this method can generate reliable and accurate results while permitting the collection of data from much larger samples.

The amount at stake (30,000 Ariary) is the equivalent of 15 meals (2000 Ariary is the average price for a meal proposed in one of the many restaurants located near the campus).

\section{(c) Control variables}

Demographic and additional general questions were asked at the end in order to avoid any potential impact they could have had on the decisions made during the experiment. Information on income, gender, origin, and religion were also gathered. Additional questions assessing risk and positional attitudes were included in order to control for any potential interactions with moral self-licensing.

Predictions regarding the effects of various socio-demographic variables on behavior in taking games are scarce in the empirical literature and the studies that are available mainly discuss gender effects. Given the symmetry between the dictator game and the taking game, we will make reference to some dictator game findings, but we do so in light of this qualification. Some studies (e.g., Bekkers, 2007 and references therein) have found that donations increase with higher income, leading us to expect a decrease in the amounts taken from individuals with higher incomes. The experimental literature also suggests that 
women behave less selfishly than men (Engel, 2011; Eckel and Grossman, 1996) and are less competitive (Gneezy, 2003). A recent paper by Chowdhury et al. (2014) found that women are more altruistic than men and allocate significantly more to the recipient in the taking game compared to the giving game. The authors observe that a "taking frame makes males significantly more selfish, but females significantly more egalitarian compared to a giving frame". In line with this research, we predict that women will take less than men. Regarding the impact of origin, we distinguish between two different subgroups: participants from the capital city (Antananarivo) and those from rural areas. In Madagascar, being from a rural area is generally associated with lower incomes and more difficult living conditions. Given that the experiment was carried out in Antananarivo, we argue that people from rural areas ('strangers') might feel less concerned about the local public good and exhibit a greater willingness to take from the University's fund (Habyarimana et al., 2007). Regarding religious identity, the available evidence is not clear-cut: while some papers find a positive impact of religious identity on giving (Shariff and Norenzayan, 2007; Ahmed and Salas, 2011), others do not (Benjamin et al., 2010). However, these differences could be due to a variety of factors and could arise, for example, from differences between those who respond according to a loose sense of religious identity vs. those who regularly attend religious services or from differences between religious converts and those who were raised in a given religion (see Brañas-Garza et al., 2014). Adherence to a religion that emphasizes the equality of human beings presumably induces people to behave more fairly and cooperatively. Christianity, for example, places a strong emphasis on sharing, and certain Protestant movements are indeed critical of gathering wealth (Hayo and Vollan, 2012).

We also created two control variables that allow us to better understand the treatment effects that may be associated with our treatments; one variable is related to risk preferences and one is related to positional preferences. To measure risk preferences, we relied on a simple elicitation method that is easy for participants to understand and is commonly used as an indicator for an individual's propensity to engage in various risk-related behaviors (Charness et al. 2013). Brock et al. (2013) found that 'the more money decision-makers transfer in the standard dictator game, the more likely they are to equalize payoff chances under risk'. For this reason, we built an index for risk preferences based on two questions from the survey. In the first question, participants were asked to indicate which option they would prefer between a sure gain of 3000 MGA (= 0 points) and $80 \%$ chance of earning 4500 MGA (= 1 point). In the second question, participants had to choose between a sure gain of 24000 MGA (= 0 points) and a $25 \%$ 
chance of earning 100000 MGA (= 2 points). The index for risk preferences is calculated by summing the points earned in these questions. The index varied from highly risk averse ( 0 points) to highly risk taking (3 points). We measure positional preferences using a binary choice that is equal to one when participants indicated they would prefer to earn a monthly salary that is lower in absolute terms, but higher than the salary of others (500 $000 \mathrm{MGA} / 400000 \mathrm{MGA}$ ) rather than a higher absolute salary that is equal to the salary of others (600 000 MGA / 600000 MGA). Lastly, Bekkers (2007) also found that generosity increases with prosocial orientation, which suggests that positional individuals (i.e., those who prefer to be worse off in absolute terms as long as they are better off than others) (Solnick and Hemenway, 1998) are more likely to take more, ceteris paribus. Despite the fact that some of the predictions regarding these preferences are far from being clear-cut, we expect that they may nonetheless prove useful in interpreting our results.

\section{RESULTS}

The characteristics of our sample (367 subjects) are presented in table 3 . The sample is well balanced across conditions, and is comprised of 51\% male subjects who report an average age of 21.64 years.

Table 3. Characteristics of participants (Percentage or mean)

\begin{tabular}{lccc}
\hline & $\begin{array}{c}\text { Control } \\
(\mathrm{n}=175)\end{array}$ & $\begin{array}{c}\text { License } \\
(\mathrm{n}=192)\end{array}$ & $\begin{array}{c}\text { Overall } \\
(\mathrm{n}=367)\end{array}$ \\
\hline Age & 21,63 & 21,64 & 21,64 \\
Male & $50 \%$ & $52 \%$ & $51 \%$ \\
Rural & $27 \%$ & $23 \%$ & $25 \%$ \\
Income & & & \\
$<50000 \mathrm{Ar} /$ month & $45 \%$ & $36 \%$ & $41 \%$ \\
$<100000 \mathrm{Ar} /$ month ; 50 000Ar/month & $31 \%$ & $36 \%$ & $33 \%$ \\
$<100000 \mathrm{Ar} /$ month & $24 \%$ & $28 \%$ & $26 \%$ \\
Religion & & & \\
Catholic & $40 \%$ & $43 \%$ & $42 \%$ \\
Protestant & $55 \%$ & $53 \%$ & $54 \%$ \\
Others 10 & $5 \%$ & $4 \%$ & $4 \%$ \\
Risk Preferences & 0.642 & 0.646 & 0.644 \\
Church attendance & 4.2 & 3.6 & 3.9 \\
Positional attitude & 0.31 & 0.33 & 0.32 \\
\hline
\end{tabular}

\footnotetext{
10 Others includes: Muslims, Hindus and Jews.
} 
Thirty-three subjects did not indicate a response in the taking game (the amount that they choose to take from the University fund). Only 3 subjects selected the opt-out clause in treatment 2. Our results are based on the remaining 331 observations. The main findings are presented below.

Finding 1: Anti-social behavior increases under moral self-licensing treatments.

Our first main result is that participants in the moral self-licensing condition (treatment 1) appear to be more willing to take from the common fund than participants in the control treatment. First, the number of participants who take money from the University's fund is greater in the moral self-licensing condition (81.66\% versus $71.74 \%$ in the control group). Furthermore, subjects who declare they would engage in a good deed for the University take 9.92 percent more from the University's fund. Second, among participants who decide to take from the common fund, subjects in the licensing group take significantly more than those in the control group ${ }^{11}$ (8.92 percent more, $\mathrm{z}=-2.957, \mathrm{p}=0.0031$ ). Of the $30,000.00$ Ariary eligible for the taking from the common fund, the average amount taken by participants is $9,528.926$ Ariary in the control group $\left(\mathrm{SEM}^{12}=906.2132\right)$ versus $13,838.1$ Ariary in the licensing group (SEM=704.3868), and this difference is statistically significant ( $\mathrm{z}=-3.771, \mathrm{p}=0.0002)$. Figures 1,2 and 3 illustrate these findings.

\footnotetext{
11 Unless otherwise specified, we use the Wilcoxon signed-rank test for statistical significance.

12 Standard Error of the Mean.
} 


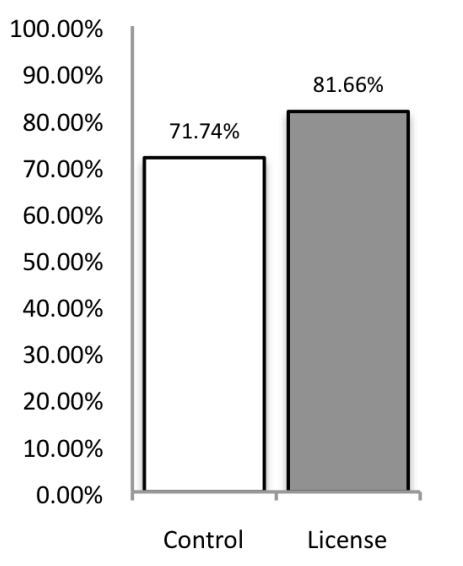

Figure 1. Share of takers in each scenario.

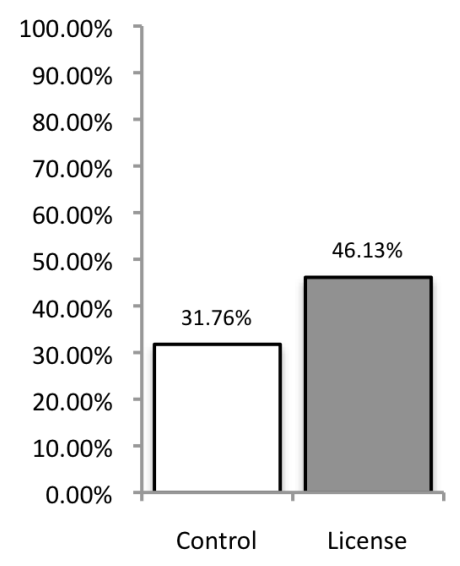

Figure 2. Share of the amount taken in each scenario.

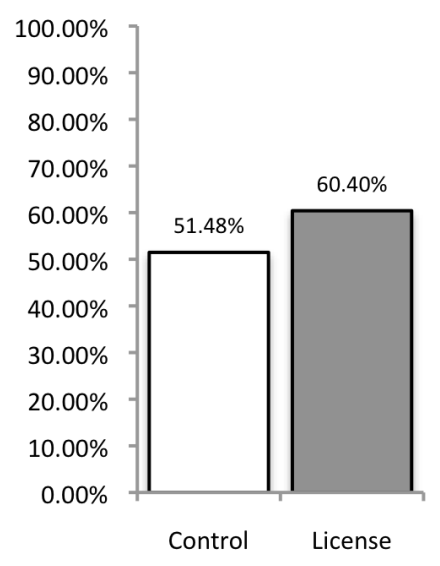

Figure 3. Share of the amount taken among takers in each scenario.

Thus, not only is there a greater proportion of students who take in the moral licensing treatment relative to the control treatment, but the average amount taken by those in the moral self-licensing treatments is also greater than the average amount taken by those in the control treatment.

A Quade test on the entire sample reveals that the average amounts taken in the four groups (the control treatment and three test treatments) are significantly different from each other at the $1 \%$ level $(\mathrm{F}=7.007$; $p=0.000$ ). Taken one by one, the three licensing treatments are also significantly different from the control treatment. ${ }^{13}$ These tests for significance are summarized in table 4 . Figure 4 summarizes the average amount taken in each treatment.

13 We use a Wilcoxon sign-rank test to test for differences between treatments and control. Although multiple paired difference tests may suffer from a compounded alpha error, the Quade statistic, as a single test, lends further support to the results. We thank an anonymous referee for raising this issue. 


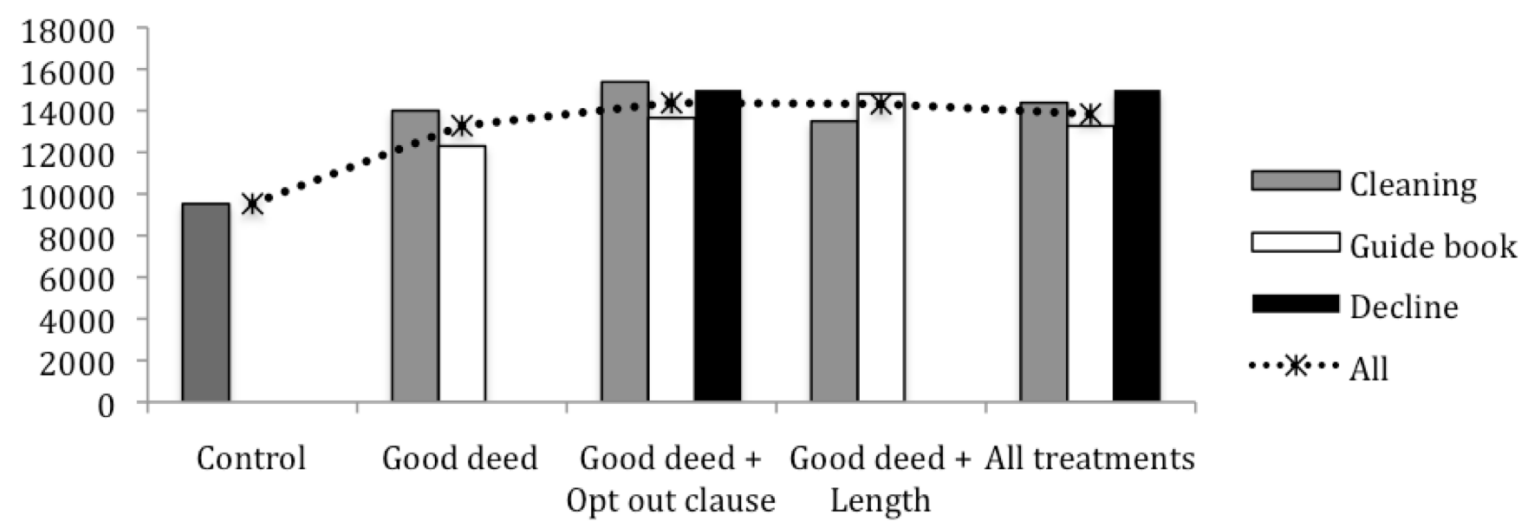

Figure 4. Average amount taken across Treatments 1, $2 \& 3$ and choices.

Table 4. Difference between treatments 1,2 \& 3 and the control treatment (Wilcoxon signed-rank test)

\begin{tabular}{ccccccc}
\hline $\begin{array}{c}\text { Control } \\
\mathrm{n}=159\end{array}$ & $\begin{array}{c}\mathrm{T} 1 \text { (Good } \\
\text { deed), } \mathrm{n}=63\end{array}$ & Control/T1 & $\begin{array}{c}\text { T2 (Good deed }+ \\
\text { Opt out clause) } \\
\mathrm{n}=66\end{array}$ & Control/T2 & $\begin{array}{c}\text { T3 (Good } \\
\text { deed+ Length), } \\
\mathrm{n}=43\end{array}$ & Control/T3 \\
\hline 9528.926 & 13277.23 & $\begin{array}{c}\mathrm{z}=-2.444 ; \\
\mathrm{p}=0.0145\end{array}$ & 14378.79 & $\begin{array}{c}\mathrm{z}=-3.438 ; \\
\mathrm{p}=0.0006\end{array}$ & 14325.58 & $\begin{array}{c}\mathrm{z}=-2.959 ; \\
\mathrm{p}=0.0031\end{array}$ \\
\hline
\end{tabular}

In the following paragraph, we discuss the different ways in which the good deed is implemented, and how these different treatments impact subsequent anti-social behavior.

Finding 2: Treatments 2 and 3 have a slightly greater effect on licensing behavior. Low investment in the good deed leads to greater anti-social behavior. A counter-intuitive magnitude effect is observed in treatment 3.

Turning now to the treatments that are designed to induce the earning of moral credits, we find that treatment 2 (good deed with an opt out option) and treatment 3 (good deed with a varying degree of investment) led to slightly greater licensing than treatment 1 (good deed with no options). Specifically, subjects in treatments 2 and 3 took approximately 1,000.00 Ariary more than those in treatment 1 (although this difference is not statistically significant). We also note that there are half as many 'no takers' (subjects choosing not to take from the fund) in treatments 2 and 3 relative to treatment 1 (13.6\% in treatment 2 and $13.9 \%$ in treatment 3 versus $26.7 \%$ in treatment 1 ). This could serve as evidence that treatments 2 and 3 are more effective in terms of earning perceived moral credits, however, no conclusive statements can be made in this regard. Moreover, we do not observe any statistical difference in terms of 
the average amount taken between the two activities (cleaning the University grounds and creating a guidebook).

Upon closer examination of treatment 3, we find that the degree of investment in the good deed significantly the degree of moral self-licensing. Specifically, subjects who indicate that they would volunteer for more than half a day take 11,821 Ariary, which is significantly $\operatorname{less}^{14}(\mathrm{z}=2.5482, \mathrm{p}=0.0147)$ than those choosing to volunteer for less than half a day, who appropriate 19,000 Ariary. We suspect that two effects may be at play here : moral licensing and moral consistency (on this issue, see Conway and Peetz, 2012; Mullen and Monin, 2016). First, a high level of commitment (volunteering for more than half a day) could promote a strong pro-social self-concept that is incompatible with a high level of anti-social behavior (moral consistency). This could be supported by the 'cognitive dissonance' effect that is often used to explain behavioral consistency. Second, a lower level of commitment (volunteering for less than half a day) may provide a moral boost in self-concept (moral licensing). Figure 6 depicts the average amount taken depending on the amount of time invested in the "licensing activity" in treatment 3.

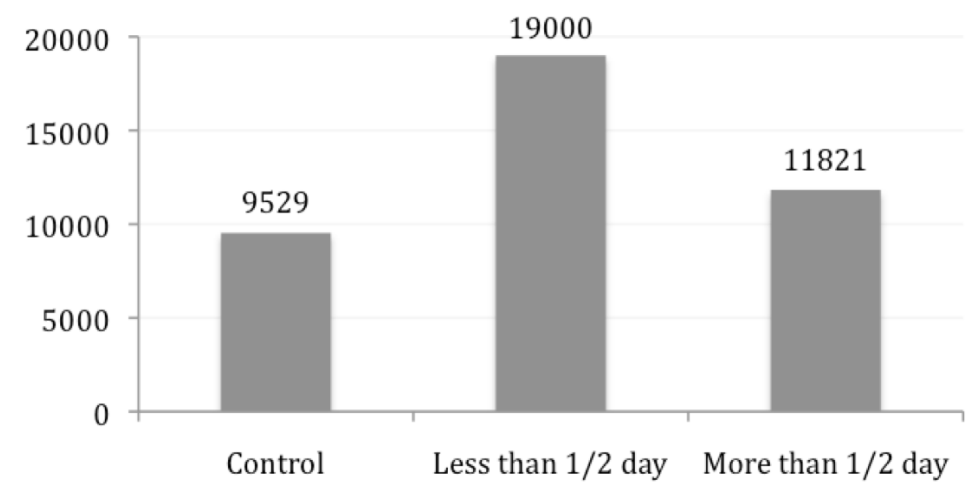

Figure 5. Average amount taken, by time of investment for the good deed.

Next, we employ a hurdle model in order to better understand the specific determinants of anti-social behavior (table 5). The first and second columns report results from the Probit model (for the binary option 'take versus no take') and the Tobit model (based on the sample restricted to positive amounts),

\footnotetext{
${ }^{14} \mathrm{~A}$ 'Wilcoxon-Mann-Whitney' non-parametric test is preferred when at least one of the two samples involved in the comparison is below 60 .
} 
respectively, which are used to identify the starting values for the first and second stages of the hurdle model.

Finding 3: Income, origin, religion, risk and positional preferences do not to affect anti-social behavior.

Regression results in the second stage of the hurdle model support our previous findings (table 5). In this model, subjects in the licensing condition take an average of 3,240.27 more than those in the control treatment. The regression also highlights the existence of a gender effect indicating, as expected, that women take less than men. The regression does not support the existence of a relationship between taking behavior and income, origin, religion, or risk preferences. Since the licensing effect is considered to be a non-conscious phenomenon (Khan and Dhar, 2006), these results are not surprising and lead us to suspect that the licensing effect could apply universally to most individuals and therefore may not differ significantly according to individuals' socio-economic characteristics.

The hurdle analysis in table 5 also demonstrates that the licensing condition plays a role in subjects decisions regarding whether or not to take from the University fund. The parameter estimate associated with being in the licensing condition (treatment 1 ) is 0.52 , which indicates that being in this condition increases the predicted probability of taking from the fund. Gender has no effect on the propensity to take in the first stage of the model, indicating that gender affects the amount taken by subjects rather than the decision to take per se. 
Table 5 : Maximum likelihood estimates from hurdle model

\begin{tabular}{|c|c|c|c|}
\hline & $\begin{array}{c}\text { Probit }(0=\text { No take } / \\
1=\text { Take })\end{array}$ & $\begin{array}{l}\text { Tobit (including positive } \\
\text { amounts only) }\end{array}$ & Hurdle \\
\hline \multicolumn{4}{|l|}{ First hurdle } \\
\hline Licensing condition & $0.36^{* *}(0.15)$ & & $0.52 *(0.29)$ \\
\hline Gender ( $=0$ if male $)$ & $0.01(0.15)$ & & $0.20(0.23)$ \\
\hline Income & $0.13(0.10)$ & & $0.11(0.13)$ \\
\hline Rural & $-0.07(0.19)$ & & $-0.15(0.24)$ \\
\hline Catholic & $-0.01(0.22)$ & & $-0.14(0.32)$ \\
\hline Protestant & $-0.12(0.20)$ & & $-0.26(0.30)$ \\
\hline Risk taker & $0.44 *(0.23)$ & & $0.59(0.40)$ \\
\hline Constant & $0.15(0.43)$ & & $0.05(0.62)$ \\
\hline \multicolumn{4}{|l|}{ Second hurdle } \\
\hline Licensing condition & & $5276.91^{* * *}(1526.41)$ & $3240.27^{* * *}(1502.73)$ \\
\hline Gender $(=0$ if male $)$ & & $-2120.56(1457.34)$ & $-3864.28^{* * *}(1462.17)$ \\
\hline Income & & 956.06 (931.99) & $396.99(853.83)$ \\
\hline Rural & & $439.52(1805.94)$ & $1574.87(1680.97)$ \\
\hline Catholic & & $1504.18(2048.84)$ & $2527.79(1937.56)$ \\
\hline Protestant & & 389.48 (1901.62) & $2189.37(1836.61)$ \\
\hline Risk taker & & 3010.65 (1954.31) & $208.84(1798.3)$ \\
\hline Constant & & $9596.41^{* *}(3860.01)$ & $18664.99 * * *(3512.50)$ \\
\hline Observations & 331 & 250 & 331 \\
\hline$p$ & 0.09 & 0.006 & 0.03 \\
\hline Chi2 & 12.27 & 19.70 & 15.17 \\
\hline $\log L$ & -171.58 & -2704.58 & -2691.30 \\
\hline
\end{tabular}

${ }^{*} p<0.10 ;{ }^{* *} p<0.05 ; * * * p<0.01$

Another interesting finding pertains to the total amount remaining in the common fund. In our experiment, we found that people appropriate on average $40.88 \%$ (12,262.84 Ariary) of the eligible amount, meaning that they leave, or share, 59.12\%. In the literature on pro-social preferences, the dictator game constitutes the standard measure of people's willingness to donate to a receiver. Meta studies of dictator games report that people generally share about 30\% of the pie (Engel, 2010). Similar games have been played in developing countries that reveal equivalent results (31\% of the pie, Henrich et al., 2005). Given that people share more than half of the pie in this study, it appears that the taking game generates higher pro-social behavior than the traditional dictator game. Although these two games are not directly comparable, this divergence indicates that manipulating framing could lead people to adopt different sharing rules. 


\section{CONCLUSIONS}

We have sought to illustrate, in a developing country context, that previous good deeds may license antisocial behavior, such as taking from a social surplus. This work provides additional insight into the motivations behind anti-social behavior and suggests how certain circumstances may threaten the creation or maintenance of social surplus. Our results contribute to the debate on whether social preferences should be considered as exogenous. Specifically, this experiment lends further empirical support to the notion that social preferences and moral behavior also depend on internal factors and could therefore vary over time as proposed by the moral credit model.

While previous studies regarding moral credits have shown that pro-social behavior can be tempered due to the moral self-licensing effect, we provide evidence that moral self-licensing can also encourage antisocial behavior and can contribute to explaining declines in a social surplus. Thus, we find that the licensing effect not only decreases the likelihood of behaving pro-socially, but it also increases the likelihood of behaving anti-socially. Having experimentally this effect in a developing country context, this work confers increased external validity to the existence of moral self-licensing behavior, adding empirical evidence that corroborates previous results found in the literature using WEIRD samples. Further evidence from the field, for example in rural areas, would be an interesting extension of this work to dispel doubts regarding the 'education' and 'welfare' components of this effect.

From a policy perspective, our research implies that, while increases in pro-social behavior are generally viewed positively by governments and societies, these increases may not represent as large a social net benefit as policymakers naturally assume. Evaluating increases in pro-social behavior without taking into account the possible counter-productive side effects that they can generate is likely to overestimate their impact. This raises the need to develop tools that enable a multidimensional evaluation of increases in pro-social behaviour. It is entirely possible, moreover, that engaging in some good deeds may license undesirable behaviors to such an extent that the bad deeds may even cancel out the positive effects of the initial good deeds. Our results furthermore suggest that the conditions under which pro-social behavior occurs (opt-out clause, varying degree of investment) can also impact subsequent licensing behavior. Pursuing further insights regarding the underlying mechanism of the moral licensing effect represents a promising area of research in the interest of minimizing the potential for negative spillovers entailed by public policies that are designed to encourage prosocial behavior. 


\section{References}

Ahmed, AM., Salas, O., 2011, Implicit influences of Christian religious representations on dictator and prisoner's dilemma game decisions, Journal of Socio-Economics, 40: 242-246.

Armantier, O. (2006). Do Wealth Differences Affect Fairness Considerations?. International Economic Review, 47(2), 391-429. doi:10.1111/j.1468-2354.2006.00383.x

Bardsley, N. (2008). Dictator game giving: altruism or artefact? Experimental Economics, 11(2), 122-133. doi:10.1007/s10683-007-9172-2

Bekkers, R., 2007, Measuring Altruistic Behavior in Surveys: The All-or-Nothing Dictator Game, Survey Research Methods, 1(3): 139-144.

Bénabou, R., \& Tirole, J. (2010). Individual and Corporate Social Responsibility. Economica, 77, 1-19. doi:10.1111/j.1468-0335.2009.00843.x

Benjamin, D., Choi, J., Fisher, G., 2010, Religious Identity and Economic Behavior', NBER Working Paper 15925, http://www.nber.org/papers/w15925.

Blanken, I, van de Ven, N., Zeelenberg, M. (2015). A meta-analytic review of moral licensing, Personality and Social Psychology Bulletin, 41(4): 540-558.

Brañas-Garza P., Espín AM., Neuman S., 2014, Religious prosociality? Experimental evidence from a sample of 766 Spaniards, PLoS ONE, 9(8), 10.1371/journal.pone.0104685.

Brañas-Garza, P. Bucheli, M., García-Muñoz, T., Espinosa A., Paz M. 2013. Moral cleansing and moral licenses: experimental evidence, Economics and Philosophy 29(2), 199-212.

Brock, JM., Lange, A., Ozbay, EY, 2013. Dictating the Risk: Experimental Evidence on Giving in Risky Environments, American Economic Review, 103(1): 415-37

Camerer, C. F. and Hogarth, R. M. (1999). The Effects of Financial Incentives in Experiments: A Review and CapitalLabor Production Framework. Journal of Risk and Uncertainty, 19, 7-42.

Cardenas, J. C., Stranlund, J., \& Willis, C. (2000). Local environmental control and institutional crowding-out. World Development, 28(10), 1719-1733.

Cardenas, J.C. \& Carpenter, J. (2008) Behavioural Development Economics: Lessons from field labs in the developing world. Journal of development Studies, 44(3), 311-338.

Carlsmith, M. J., \& Gross, A. E. (1969). Some Effects Of Guilt On Compliance, Journal of Personality and Social Psychology, 11(3), 232-239. 
Carpenter, J. P., \& Seki, E. (2010). Do social preferences increase productivity? Field experimental evidence from fishermen in Toyama bay. Economic Inquiry, 49(2), 612-630.

Castillo, D., \& Saysel, A. K. (2005). Simulation of common pool resource field experiments: A behavioural model of collective action. Ecological Economics, 55(3), 420-436.

Charness, G., Gneezy, U. and Imas, A. (2013) Experimental methods: eliciting risk preferences. Journal of Economic Behavior \& Organization, 87, 43-51.

Chiou, W.-B., Wan, C.-S., Wu, W.-H., \& Lee, K.-T. (2011). A randomized experiment to examine unintended consequences of dietary supplement use among daily smokers: taking supplements reduces self-regulation of smoking. Addiction (Abingdon, England), 106(12), 2221-8. doi:10.1111/j.1360-0443.2011.03545.x

Chowdhury, S.M., Jeon, J.Y., Saha, B., 2014. Giving, taking, and gender in dictator games (No. 14-09). School of Economics, University of East Anglia, Norwich, UK.

Clot, S., Grolleau, G. and Ibanez, L. (2014). Self-Licensing and Financial Rewards: Is Morality For Sale? Economics Bulletin, 33(3), 2298-2306.

Clot, S., Grolleau, G. and Ibanez, L. (2014) Smug alert! Exploring self-licensing behaviour in a cheating game. Economics Letters, 123 (2), 191-194.

Clot, S., Grolleau, G. and Ibanez, L. (2016). Do good deeds make bad people? European Journal of Law and Economics, 42 (3), 491-513. ISSN 0929-1261 doi: 10.1007/s10657-014-9441-4

Conway, P, Peetz, J. (2012). When does feeling moral actually make you a better person? Conceptual abstraction moderates whether past moral deeds motivate consistency or compensatory behavior, Personality and Social Psychology Bulletin, 38(7), 907-919.

Cox, J.C., Ostrom, E., Sadiraj, V., Walker, J.M. (2013). Provision versus Appropriation in Symmetric and Asymmetric Social Dilemmas. Southern Economic Journal, 79(3), 496-512.

Eckel, C. C., \& Grossman, P. J. (1996). The relative price of fairness: gender differences in a punishment game. Journal of Economic Behavior \& Organisation, 30, 143-158.

Effron, D. A., \& Merritt, A. C. (2010). Moral Self-Licensing : When Being Good Frees Us to Be Bad. Social and Personality Psychology Compas, 5(4), 344-357.

Eichenberger, R., \& Oberholzer-gee, F. (1998). Rational moralists : The role of fairness in democratic economic politics. Public Choice, 94, 191-210.

Engel, C. (2011). Dictator games: a meta study. Experimental Economics, 14(4), 583-610. doi:10.1007/s10683-0119283-7 
Effron, D. A. and Monin, B. (2010). Letting people off the hook: When do good deeds excuse transgressions? Personality and Social Psychology Bulletin, 36, 1618-1634.

Gneezy, U. (2003). The W effect of incentives. Working Paper, The University of Chicago Graduate School of Business.

Gneezy, U., Imas, A., Madarász, K. (2014). Conscience Accounting: Emotion Dynamics and Social Behavior. Management Science, 60(11), 2645-2658.

Habyarimana, J., Humphreys, M., Posner, D. N., \& Weinstein, J. M. (2007). Why Does Ethnic Diversity Undermine Public Goods Provision? American Political Science Review, 101(4), 709-725. doi:10.1017/S0003055407070499

Hayo, B., \& Vollan, B. (2012). Group interaction, heterogeneity, rules, and co-operative behaviour: Evidence from a common-pool resource experiment in South Africa and Namibia. Journal of Economic Behavior \& Organization, 81(1), 9-28. doi:10.1016/j.jebo.2011.09.002

Henrich, J. (2000). Does culture matter in economic behaviour? Ultimatum game bargaining among the Machiguenga of the Peruvian Amazon. American Economic Review, 90(4), 973-979.

Henrich, J., Boyd, R., Bowles, S., Camerer, C., Fehr, E., Mcelreath, R., Alvard, M., et al. (2005). “ Economic Man ” in Crosscultural Perspective : Behavioral Experiments in 15 Small-scale Societies. Behavioral and Brain Sciences, 28(6), 815-855.

Henrich J, Heine S. J, Norenzayan A., 2010, The weirdest people in the world? Behavioral Brain Sciences, 33(2),61-83.

Khan, U., \& Dhar, R. (2006). Licensing Effect in Consumer Choice. Journal of Marketing Research, 43, 357-365.

Locey, M. L., Jones, B. A., and Rachlin, H. (2011). Real and hypothetical rewards. Judgment and decision making, 6(6), $552-564$.

Mazar, N., \& Zhong, C.-B. (2010). Do Green Products Make Us Better People? Psychological Science, 21, 494-498.

Mullen, E. Monin, B. (2016). Consistency Versus Licensing Effects of Past Moral Behavior, Annual Review of Psychology, 67: 363-385.

Narloch, U., Pascual, U., \& Drucker, A. G. (2012). Collective Action Dynamics under External Rewards: Experimental Insights from Andean Farming Communities. World Development, 40(10), 2096-2107. doi:10.1016/j.worlddev.2012.03.014

Panzone, L.A., Wossink, A., Southerton, D. (2012). Environmental performance and offsetting behaviour : Moral self licensing in consumer choice. Working paper, Newcastle University.

Sachdeva, S., Iliev, R., Medin, D., (2009), Sinning Saints and Saintly Sinners: The paradox of Moral Self-Regulation. Psychological Science, 20 (4), 523-528. 
Shariff, AF., Norenzayan, A., 2007, God Is Watching You: Priming God Concepts Increases Prosocial Behavior in an Anonymous Economic Game, Psychological Science, 18: 803-809.

Solnick, S.J., Hemenway, D. (1998), Is more always better?: A survey on positional concerns. Journal of Economic Behavior \& Organization, 37(3), 373-383. doi: 10.1016/S0167-2681(98)00089-4

Tiefenbeck, V., Staake, T., Roth, K., and Sachs, O. (2013). For better or for worse? Empirical evidence of moral licensing in a behavioral energy conservation campaign. Energy Policy, 57, 160-171.

Velez, M. A., Stranlund, J. K., \& Murphy, J. J. (2009). What motivates common pool resource users? Experimental evidence from the field. Journal of Economic Behaviour and Organization, 70(3), 485-497.

Vollan, B. (2008). Socio-ecological explanations for crowding-out effects from economic field experiments in southern Africa. Ecological Economics, 67(4), 560-573.

Woodyard, C. (2009), Hybrid car owners drive more and get more traffic tickets. Usa Today. http://content.usatoday.com/communities/driveon/post/2009/07/6849 4710/1 